Fourth International Conference on Sustainable Construction Materials and Technologies http://www.claisse.info/Proceedings.htm

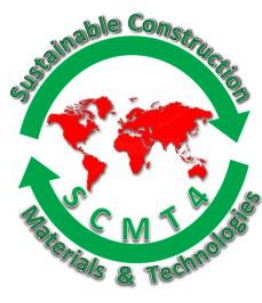

SCMT4

Las Vegas, USA, August 7-11, 2016

\title{
An Experimental Study of the Concrete Using Polymer and Metakaolin as Additives
}

\author{
Adel Al Menhosh'ia, Yan Wang ${ }^{2}$, and Yu Wang ${ }^{1 \mathrm{~b}}$ \\ ${ }^{1}$ School of Computing, Science \& Engineering, University of Salford, Manchester M5 4WT, UK. \\ ${ }^{1 a}$ Email: <adelahmed9566@yahoo.com>, ${ }^{1 b}$ Email: <y.wang@salford.ac.uk> \\ ${ }^{2}$ School of Civil Engineering, Chongqing Jiaotong University, Chongqing, P.R. China. \\ ${ }^{2}$ Email: 〈wangyan@cqjtu.edu.cn>
}

\begin{abstract}
Environmental friendly and high performance concrete is very import for the applications in sewage and water treatment industry. Using mineral additives such as fly ash and silica fume has been proven an effective approach to improve concrete properties. This paper reports a study of the effect of using both polymer and metakaolin additives together on the mechanical and durability properties of concrete. Different proportion of the combination using two different polymers, metakaolin and recycled fiber reinforcement have been studied. The effects of water to cement ratio and the curing methods have also been compared. At last an optimized mixture and curing method has been suggested.
\end{abstract}

\section{INTRODUCTION}

Using mineral additives such as fly ash and silica fume has been proven an effective approach to improve concrete properties. With the increasing of the environmental concern, in recent years [Srinivasu, et.al. 2014], the use of Metakaolin (MK) as an optional additive has also raised more and more interests [Aiswarya et al 2013]. As a supplementary cementitious material MK has the expected pozzolanic nature activated by tri-calcium silicate (C3S) and tri-calcium aluminate (C3A) [Jean 1994]. When used as a partial replacement for cement, MK reacts with Portlandite $\left(\mathrm{Ca}(\mathrm{OH})_{2}\right)$ to generate additional CSH gel which results in the increase of strength. Previous work by Khatib et al. [2012] showed that the $20 \%$ replacement of cement using MK had resulted in a substantial 50\% increase of the compressive strength of mortar. However, with over $30 \%$ replacement of cement by MK, the compressive strength started to decrease. It has also been shown that the sample containing 10\% MK replacement displayed the best performance in terms of ultrasonic test. Joy [2005] compared the effects of the use of two different types of MK on concrete workability and setting time. It was found that MK caused a considerable reduction in workability, and reduced the setting time of cement paste by $35-50 \%$. The study also showed that the use of MK had increased the compressive strength, splitting tensile strength, flexural strength, and the elastic modulus of concrete samples. Erhan et al. [2012] compared the effects of the use of silica fume and MK on the water sorptivity of concrete. It was observed that the water sorptivity decrease more using MK additive than using silica fume. 
In concrete practice, polymers have been also commonly used as additives to improve concrete durability because of its effect on reducing water absorption. Styrene butadiene rubber (SBR) and poly vinyl acetate (PVA) are two polymers commonly used into concrete with the effect on reducing the pore spaces and connection [Fowler 1987]. Previous work [Bhikshma et al. 2010] has found that, while increases the strength and decease the water permeability, SBR can increase the workability of concrete as well. The work by Jamshidi and Pakravan [2014] also showed that a polymer admixture of the SBR, Acrylic and PVA generated a decrease in water permeability of the concretes. A work by Lewis and Lewis [1990] showed that the workability of SBR-modified concretes was much higher than that of normal concrete, and increases with the increase of polymer content. However, the workable time was greatly reduced when compared with normal unmodified concrete. Wang et al. [2005] studied the physical and mechanical properties of SBR modified cement mortars using different polymer/cement ratio $(\mathrm{p} / \mathrm{c})$ and a constant water/cement ratio of 0.4. They also compared two curing methods, i.e.: wet cure for 2,6 or 27 days by immersed in $20^{\circ} \mathrm{C}$ water, and mixed cure for 6 days by immersed in $20^{\circ} \mathrm{C}$ water followed by 21 days at $20^{\circ} \mathrm{C}$ and $70 \%$ relative humidity $(\mathrm{RH})$. The results showed that the mixed cure produced an improvement on the mortar properties. Tomas and Ganiron [2013] ever investigated the influence of polymer fiber on the strength of concrete. They added two kinds of polymer fibers, i.e.: polyvinyl alcohol and polyvinyl acetate, into concrete mixes. It was found that the polymer modified concrete of $2 \% \mathrm{p} / \mathrm{c}$ showed the highest compressive strength and that of $6 \% \mathrm{p} / \mathrm{c}$ displayed a similar result as that of the conventional concrete.

\section{EXPERIMENTAL INVESTIGATION}

This research aims to investigate the combined effect using both MK and polymer together on the improvement of the concrete mechanical and durability properties. At first, control sample was made using a mixture of Portland cement, sand, and gravels. At second, modified concrete specimens were made by adding two types of polymer additives, they are SBR and PVA, and partially replacing the cement using MK. Different water cement ratios were used for all of these mixtures. In addition, plastic and glass fiber made of recycled materials were used to reinforce the concrete mixtures. Experimental tests of the concrete mixtures after different setting time have been carried for mechanical properties, including: compressive strength, splitting tensile strength, flexural strength, and the durability related property, the water absorption. The effects of using different curing methods have also been compared.

Component materials and mixtures. Portland limestone cement, the CEM II/A-LL (BS EN 1971:2011), was used in the experiment. The cement properties have been listed in the Table 1. The fine aggregate used sand, while the coarse aggregate was crashed limestone and conventional gravel with maximum size of $10 \mathrm{~mm}$. Their particle size distribution followed the BS 882:1992 and BS 812: 1992. A premium metakaolin produced by Whitchem Ltd (http://whitchem.co.uk/) was used in this study. Its properties have been shown in Table 2. Both SBR and PVA were used as polymer additives. Tables 3-4 have listed out their proprieties, respectively. Alkali resistant glass fibre (GF) and a recycled polypropylene plastic fibre (PF) were also used in the study.

Table 1. Properties of the cement used

\begin{tabular}{|c|c|c|c|}
\hline \multicolumn{1}{|c|}{ Particulars } & Unite & value & Standard \\
\hline Setting time - initial & (minutes) & 150 & $80-200$ \\
\hline compressive strength & & & \\
\hline 2 day & $\left(\mathrm{N} / \mathrm{mm}^{2}\right)$ & 17 & $16-26$ \\
\hline 7 day & $\left(\mathrm{N} / \mathrm{mm}^{2}\right)$ & 29 & $27-37$ \\
\hline 28 day & $\left(\mathrm{N} / \mathrm{mm}^{2}\right)$ & 40 & $37-47$ \\
\hline
\end{tabular}


Table 2. Metakaolin properties

\begin{tabular}{|l|c|}
\hline Particulars & Value \\
\hline Colour & White \\
\hline ISO Brightness & $>82.5$ \\
\hline$-2 \mu \mathrm{m}($ mass $\%)$ & $>60$ \\
\hline+325 mesh (mass \%) & $<0.03$ \\
\hline Moisture (mass \%) & $<1.0$ \\
\hline Aerated powder density $\left(\mathrm{kg} / \mathrm{m}^{3}\right)$ & 320 \\
\hline Tapped powder density $\left(\mathrm{kg} / \mathrm{m}^{3}\right)$ & 620 \\
\hline Surface area $\left(\mathrm{m}^{2} / \mathrm{g}\right)$ & 14 \\
\hline Pozzolanas reactivity $\left(\mathrm{mg} \mathrm{Ca}(\mathrm{OH})_{2} / \mathrm{g}\right)$ & $>950$ \\
\hline
\end{tabular}

Table 3. Styrene butadiene rubber properties

\begin{tabular}{|l|c|}
\hline \multicolumn{1}{|c|}{ Particulars } & Value \\
\hline Brand & Cementone \\
\hline Colour & White \\
\hline Model Name & SBR \\
\hline Product Type & Admixture \\
\hline Resistant Type & Water, Chemical \& Abrasion Resistance \\
\hline
\end{tabular}

Table 4. Poly vinyl acetate properties

\begin{tabular}{|l|c|}
\hline \multicolumn{1}{|c|}{ Particulars } & Values \\
\hline $\begin{array}{l}\text { Typical Performance Data(approx.) } \\
\text { Application Temperature }\end{array}$ & $5^{\circ} \mathrm{C}-25^{\circ} \mathrm{C}$. \\
\hline Wet grab & 10 minutes approx. at $15^{\circ} \mathrm{C}$. \\
\hline Tack Development & $10-90$ minutes at $15^{\circ} \mathrm{C}$. \\
\hline Bonding & Maximum strength is attained in 24 hours. \\
\hline Colour & white \\
\hline Form & Liquid \\
\hline Specific Gravity & 1.1 approx. \\
\hline Composition & Polyvinyl Acetate Emulsion \\
\hline
\end{tabular}

The control concrete mixture took the proportion of cement/sand/gravel as $1 / 1.5 / 3$. The modified mixtures were made based on the control mix with the replacement of the cement using MK and a polymer mixture. The MK took $0,10,15$ and $20 \%$ of the weight of cement, respectively, while the polymer mixture took $0,2.5,5$ and $7.5 \%$, respectively. The added fibre took the $0,2.5$ and $5 \%$ of the cement weight of the control mixture. The mixtures are listed in Table 5. The effect of three water-to-cement 
ratios, the $0.35,0.4$ and 0.45 , were studied based on the control mix. The effect of three curing methods, the wet, dry and moist, were also compared.

Table 5. The Mixtures Proportion Used in This Study

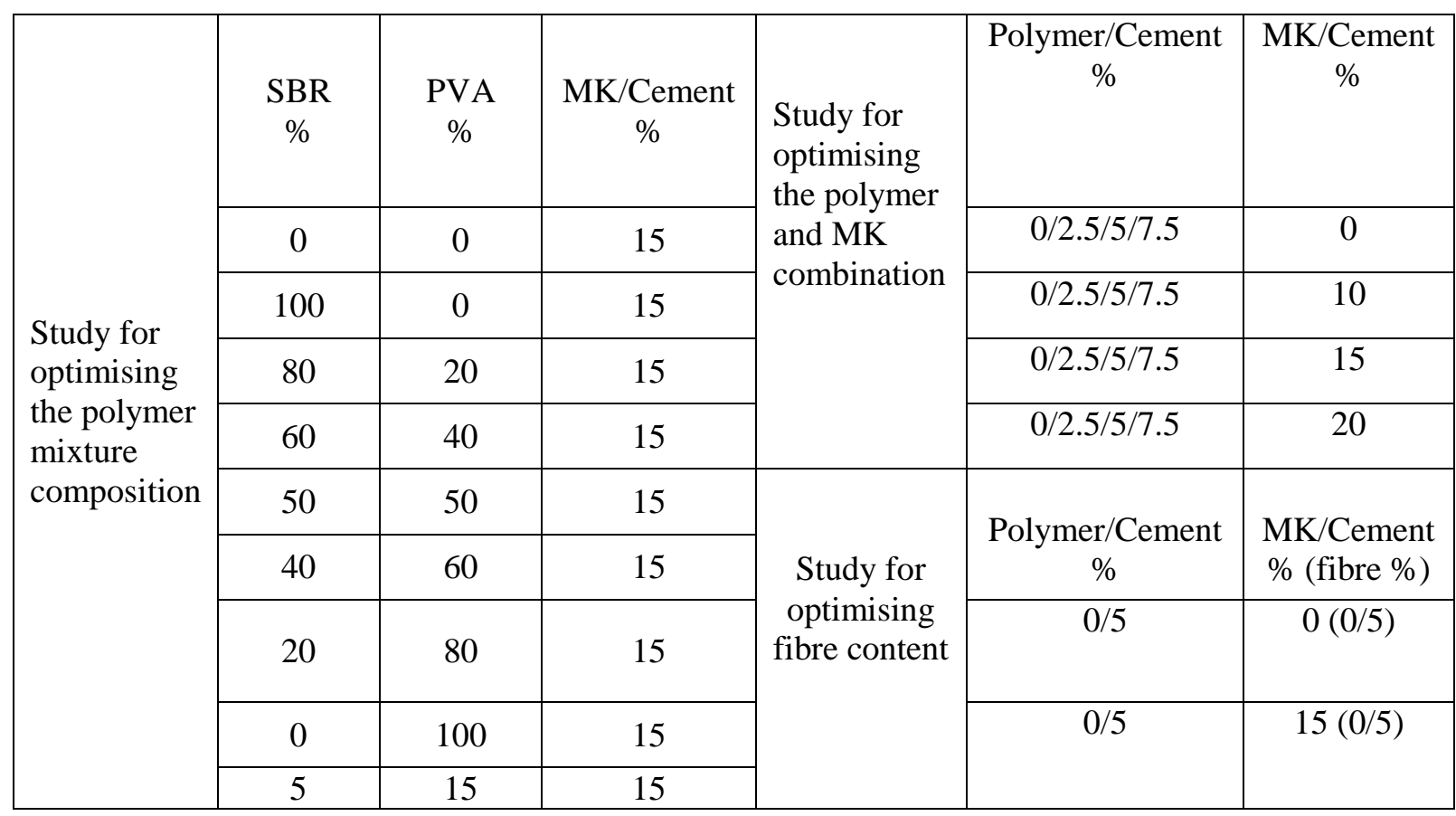

Experimental tests. Setting time: the initial and final setting time tests were conducted on cement pastes for a standard consistency. The consistence was measured using Vicat apparatus according to ASTM C187-86:1986. The sitting time was measured according to the penetration of a needle gauge according to ASTM C 191-82: 1986.

Slump test: the workability of mixtures was tested following the BS EN 12350-2:2009.

Compressive strength: compressive test was conducted using cubic samples with a dimension of 100 (L) by $100(\mathrm{D})$ by $100(\mathrm{H}) \mathrm{mm}$ according to the BS 1881 part 116: 1983.

Splitting tensile strength: splitting tensile test was conducted using cylindrical samples with a dimension of 150 (D) by 300 (L) mm according to the BS 1881 Part 117: 1983.

Flexural strength: flexural test was conducted using prismatic samples with a dimension of 100 (D) by $100(\mathrm{H})$ by 500 (L) by applying a concentrated load at the center according to ASTM C293-02.

Water absorption: water adsorption test was conducted using cubic samples with the dimension same as that used for compressive test according to B.S. 1881: part 122: 2011.

\section{RESULTS AND DISCUSSIONS}

Figures 1-3 have showed the results of the initial and final setting times. It can be seen that polymer has a significant effect on delaying setting time. The effect increases with the increase of polymer content. It also can be seen that the setting time accelerates with the increase of MK content. With the addition of both polymer and MK, it has been found that the mixture of $15 \%$ MK displayed a relatively stable setting time at varied polymer contents. 


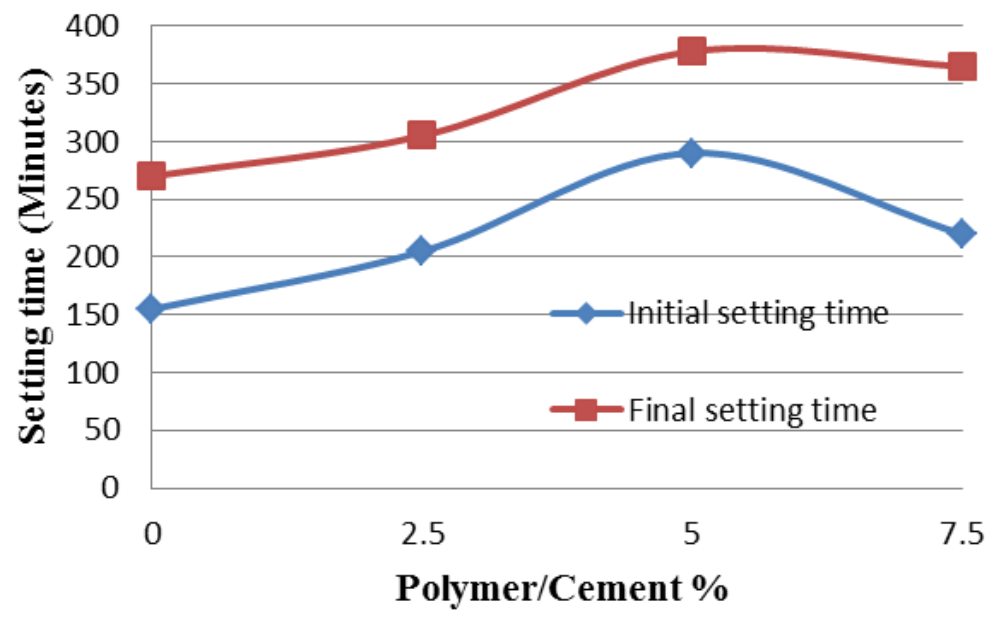

Figure 1. The Setting Time of Polymer Modified Cement Paste with 0\% MK

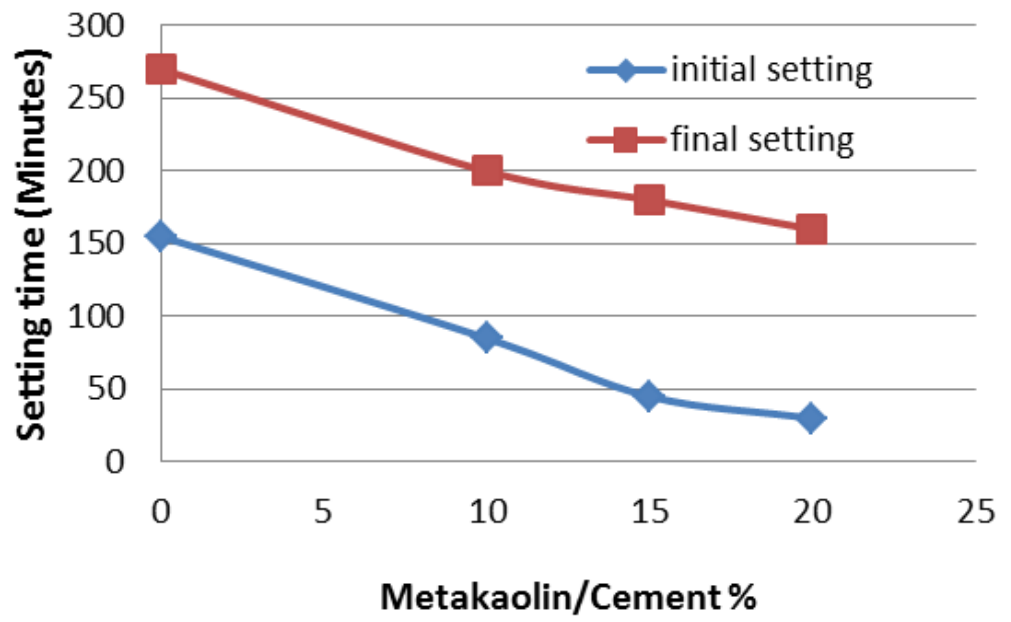

Figure 2. The Setting Time of MK Modified Cement Paste with 0\% Polymer

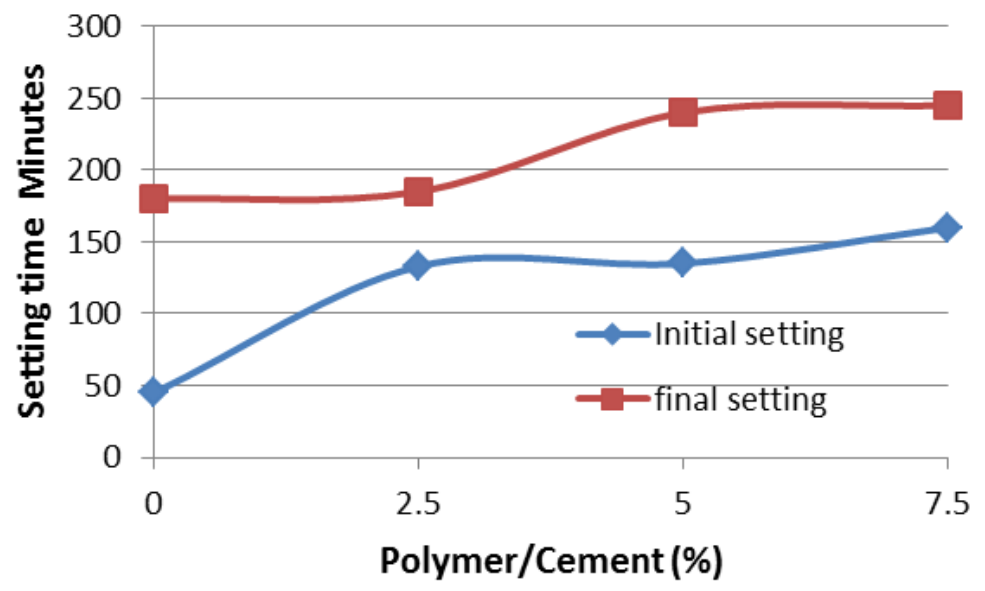

Figure 3: The Setting Time of Polymer Modified Cement Paste with 15\% MK 
Figure 4 shows that the workability increases with the increase of polymer content, but decreases with the increase of MK, and the similar results were observed for all w/c ratios.

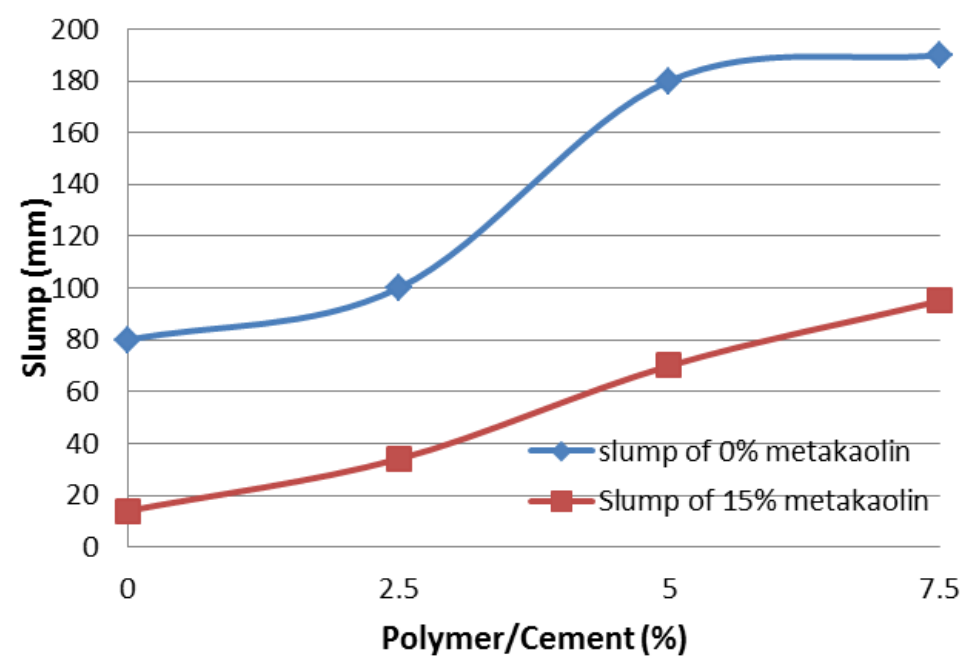

Figure 4. Effect of Polymer and MK on Workability for modified concrete with w/c 45\%

The effect of the polymer of different composition of the SBR and PVA was studied. Figure 5 shows that the polymer consisting of $80 \%$ SBR and $20 \%$ PVA displays the highest compressive strength. Figures 6-8 show the effect of varied contents of the polymer consisting of $80 \%$ SBR and $20 \%$ PVA, and MK on the compressive strength. It can be seen that the mixture of 5\% polymer and $15 \%$ MK displayed the highest compressive strength. It also can be seen that while the 28 days compressive strength decreases when polymer content exceeds 5\%, however, both 7 days and 28 days compressive strengths increase with the increase of MK. Figures 9 and 10 show the effect of different curing methods on the compressive strength of the modified concretes. It can be seen that the moist curing generated the best results. Figure 11 shows the results using different types of coarse aggregates. It can be seen that limestone aggregate is better than normal aggregate.

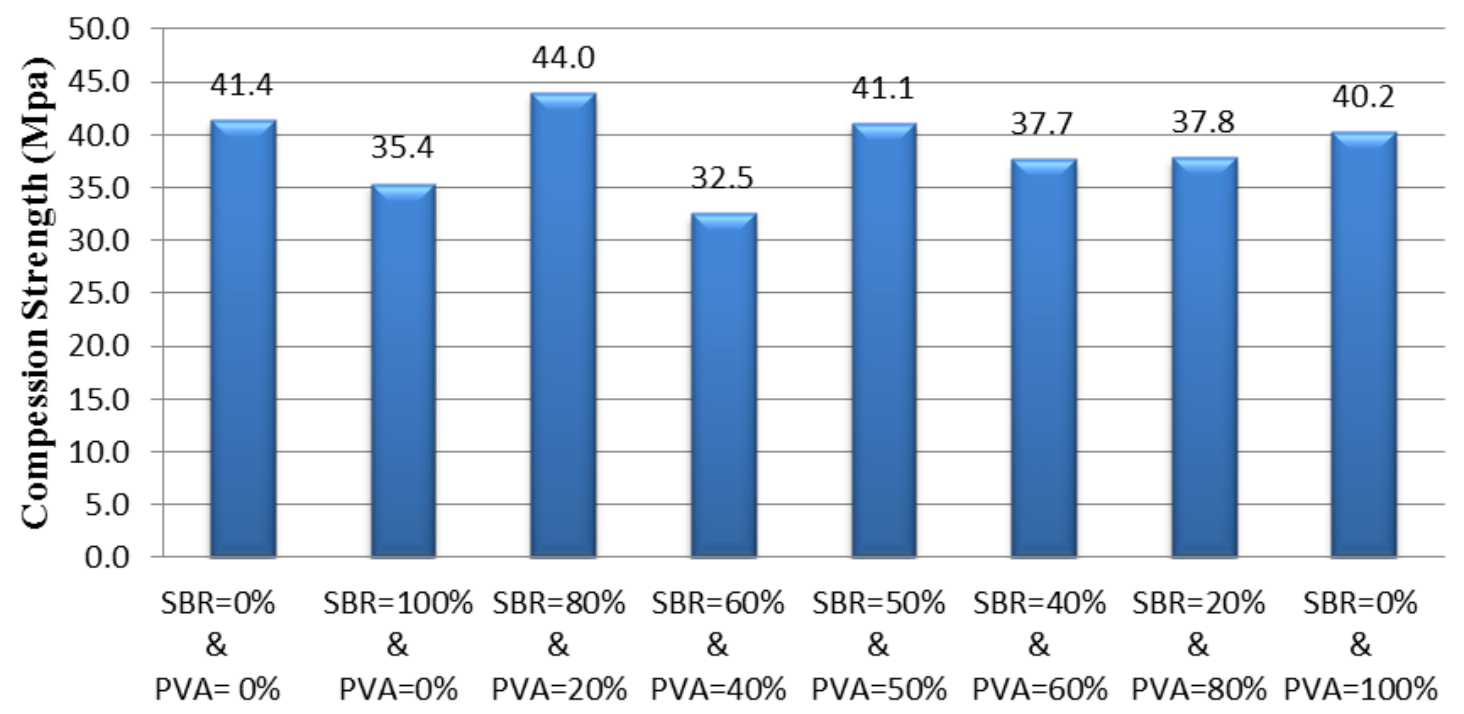

Figure 5. 28 Days Compressive Strength of the Concrete Containing 5\% Polymer and 15\% 
MK

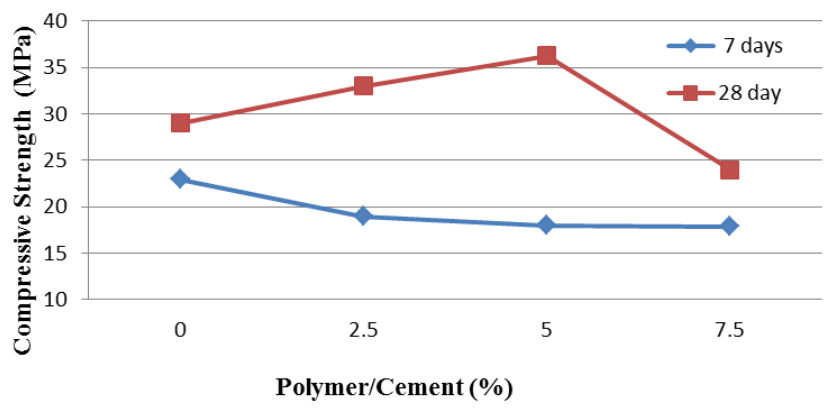

Figure 6. The Compressive Strength at Different Polymer Contents with $0 \% \mathrm{M} / \mathrm{C}$ and $\mathrm{W} / \mathrm{C}=\mathbf{4 5} \%$

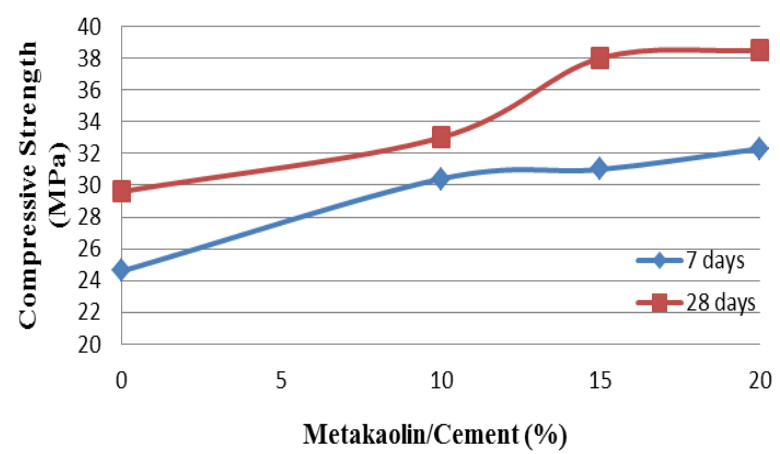

Figure 7. The Compressive Strength at Different MK Contents and 0\% Polymer

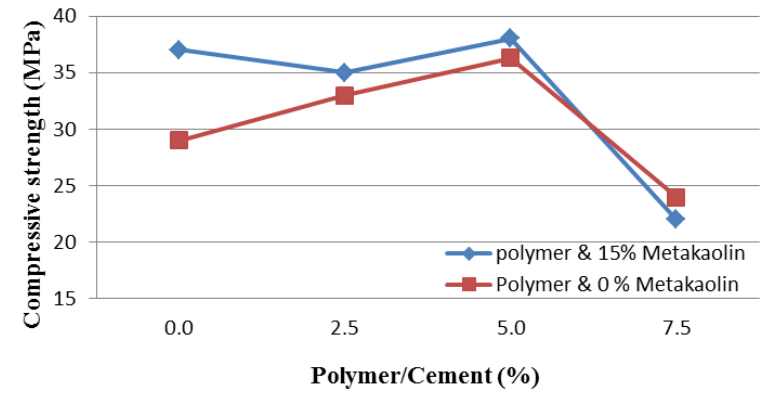

Figure 8. The Compressive Strength at Different Polymer Contents at age 28 days

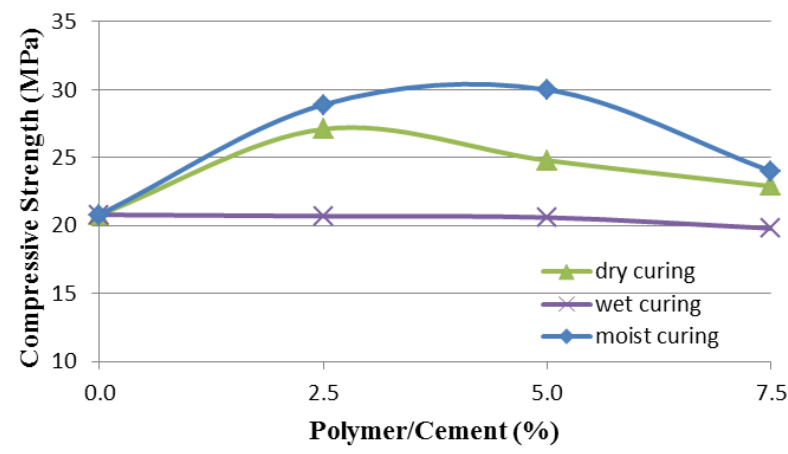

Figure 9. The Effect of Curing Methods on the Compressive Strength at Different Polymer 


\section{Contents and $0 \%$ MK at age 28 days}

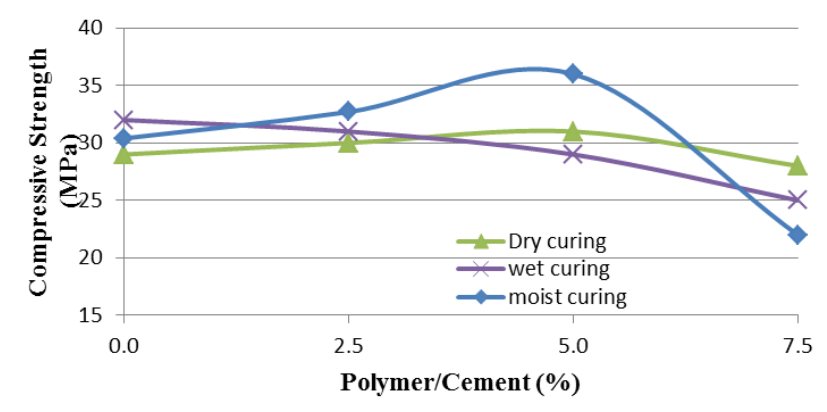

Figure 10. The Effect of Curing Methods on the Compressive Strength at Different Polymer Contents and $15 \%$ MK at age 28 days

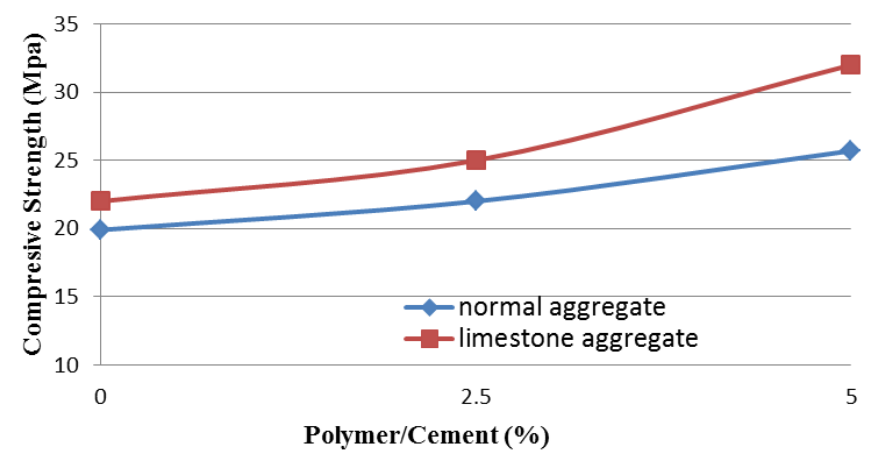

Figure 11. The Effect of the Aggregates type on the Compressive Strength at Different Polymer Content and $0 \%$ MK at age 28 days

Figure 12 shows the effect of plastic fiber (PF) and glass fiber (GF) on the splitting tensile strength. It can be seen that using glass fiber for reinforcement produced the highest splitting strength.

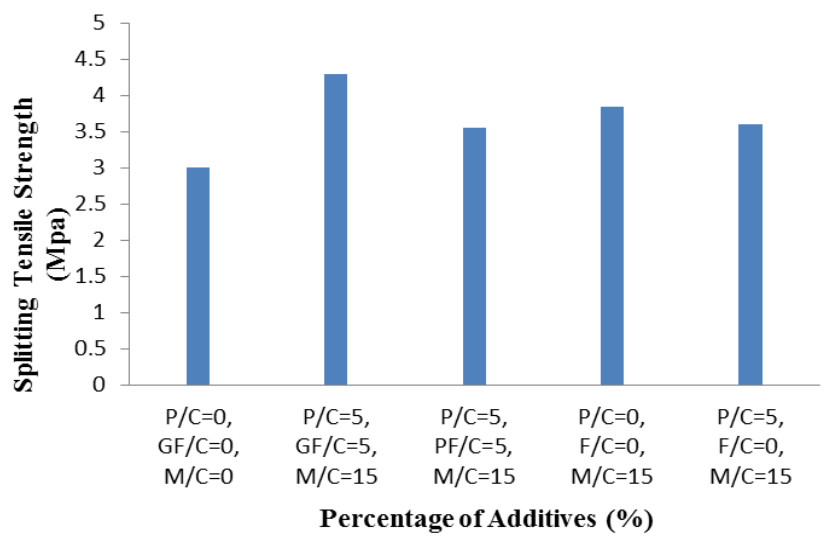

Figure 12. Splitting Tensile Strength at Age of 28 Days

Figure 13 shows the effect of fiber reinforcement on flexural strength. It can be shown that the flexural strength has been improved with the fiber reinforcement. The use of glass fiber (GF) and polymer presents the best flexural strength. It also can be seen that using MK will enhance the flexural strength as well. However, using both MK and polymer together, the mixture shows a decrease in flexural strength. To explain this, further study is needed. 


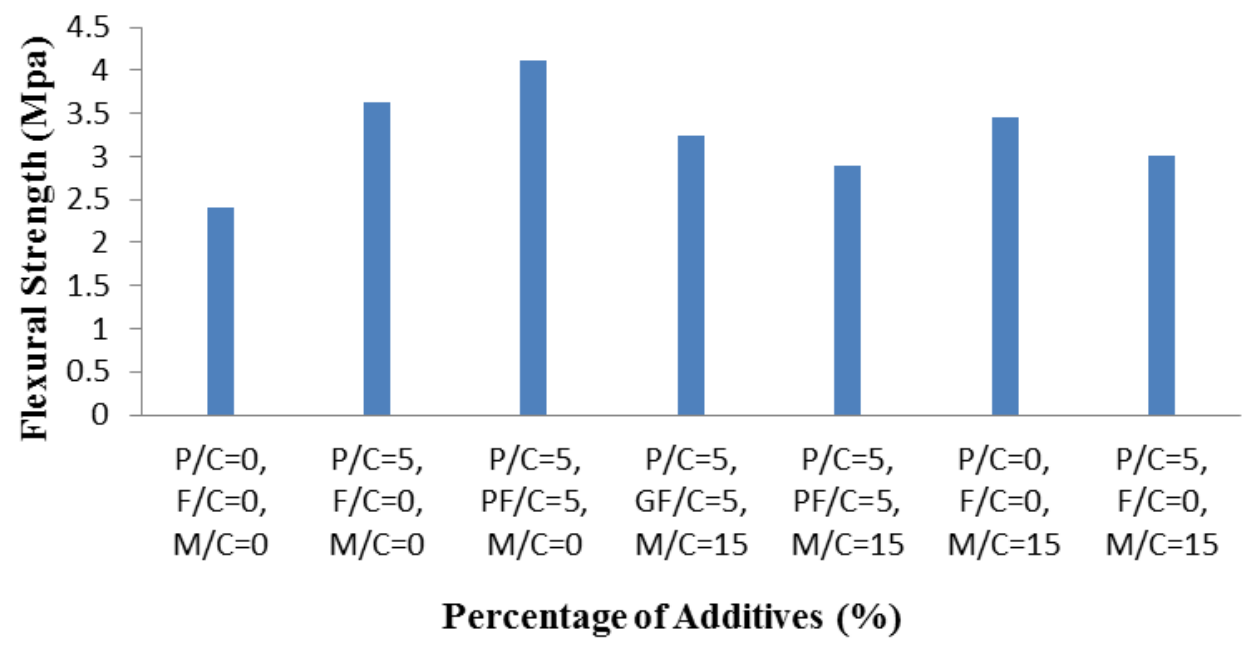

Figure 13. Flexural strength at age 28 days

Figures 14 and 15 show the total adsorbed water percentage in terms of the weight of dry samples. It can be seen that with the increase of polymer and MK content, the water absorption reduces remarkably. This might be due to a reduction in porosity as the result of the added polymer latex and the pozzolanic reaction of Metakaolin.

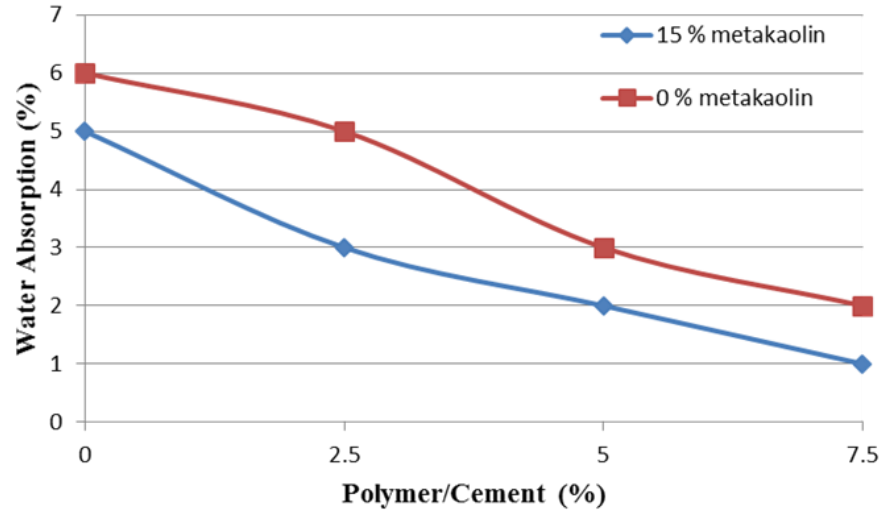

Figure 14. Water Absorption at Different Polymer Contents

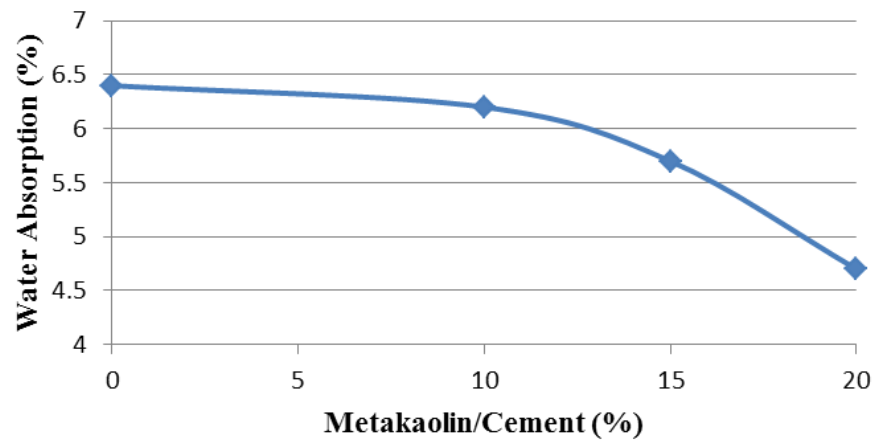

Figure 15. Water Absorption at Different MK Contents and $0 \%$ polymer 


\section{CONCLUSION}

The following conclusions can be drawn from the reported experimental study:

- Metakaolin will accelerate the setting time of cement pastes, but reduce the workability of concrete. However, polymer has an inverse influence on the two properties.

- The polymer composition of $80 \%$ SBR and $20 \%$ PVA shows an optimized result when work together with the MK.

- The appropriate water/cement ratio is 0.45 for the concrete using polymer and Metakaolin additives.

- That the addition of 5\% optimized Polymer and 15\% cement replacement using Metakaolin generates an optimized concrete mixture for both strength and durability.

- For the optimized Polymer and MK mixture, the 5\%, in terms of the cement weight, addition of the plastic and glass fibres can effectively improve the tensile strength.

\section{REFERENCES}

Aiswarya, S., Prince D. and Dilip, C., (2013) "a Review on Use of Metakaolin in Concrete Abstract: Engineering Science and Technology": An International Journal, 3(3), 592-597.

Bhikshma,V., Jagannadha, K. and Rao, (2010) "An experimental study on behaviour of polymer cement concrete",Asian journal of civil engineering Vol.11,No.5.

Erhan , G., Mehmet,G., Seda, K. and Kasim,M. (2012). "Strength, permeability and shrinkage cracking of silica fume and metakaolin concretes". Construction and Building Materials, 34, 120-130.

Fowler, D W. (1987), "Polymer in concrete" , Hand book of structural concrete , Mc Graw-Hill, New York.

Jamshidi, M. Pakravan, H. Pourkhorshidi, A. (2014). "Application of polymer admixtures to modify cocrete properties". Effect of polymer type and content. , 15(5),779-78.

Jean A., Maximilien S., and Pera J., (1994). "Properties of Metakaolin Blended Cement"s Advn Cem Bas Mat Vol $1,161-168$.

Joy M. (2005). "Evaluation of Metakaolin for use as supplementary cementitious materials", MSc. thesis , The Academic Faculty, Georgia Institute of Technology.

Khatib, J.M., Negim, E.M. \& Gjonbalaj, E.,(2012). "High Volume Metakaolin as Cement Replacement in Mortar". M(1),7-10.

Lewis, W.J. \& Lewis, G., (1990). "The influence of polymer latex modifiers on the properties of concrete". , 21(6), 487-494.

Neville, A. M.,(2002). "Properties of concrete" ,Book, 4th Edi. London: Pearson Education Limited.

Srinivasu, K., Sai, M.L.N.K. \& N, V.S.K., 2014. A Review on Use of Metakaolin in Cement Mortar and Concrete. , 3(7).14697-14701.

Tomas U. Ganiron Jr, (2013). "Influence of Polymer Fiber on Strength of Concrete", International Journal of Advanced Science and Technology Vol. 55.

Wang, R., Wang, P.M. and Li, X.G., (2005). "Physical and mechanical properties of styrene-butadiene rubber emulsion modified cement mortars". Cement and Concrete Research, 35(5),900-906. 